Rhode Island College

Digital Commons @ RIC

Faculty Publications

Faculty Scholarship

2010

Developing Library Websites Optimized for Mobile Devices

Brendan Ryan

Rhode Island College

Follow this and additional works at: https://digitalcommons.ric.edu/facultypublications

Part of the Other Education Commons

\title{
Citation
}

Ryan, Brendan, "Developing Library Websites Optimized for Mobile Devices" (2010). Faculty Publications.

441.

https://digitalcommons.ric.edu/facultypublications/441

This Article is brought to you for free and open access by the Faculty Scholarship at Digital Commons @ RIC. It has been accepted for inclusion in Faculty Publications by an authorized administrator of Digital Commons @ RIC. For more information, please contact digitalcommons@ric.edu. 


\section{Developing Library Websites Optimized for Mobile Devices}

Brendan Ryan

\section{RHODE ISLAND COLLEGE}


(c) (i)(2)

Developing Library Websites Optimized for Mobile Devices by Brendan Ryan is licensed under a Creative Commons AttributionNonCommercial-ShareAlike 3.0 Unported License.

This book was produced using PressBooks.com. 


\section{Abstract}

The article explores the development of library websites optimized for mobile devices. Topics to be covered will include beginning the process of developing for mobile devices, assessing project goals, text-based contact with library staff, and mobile device emulators. 


\section{Introduction}

Mobile devices are becoming a fixture of contemporary life. They are coming to be the primary means for communication and access to the internet for many people. In light of this situation, anticipating future developments, and to meet the needs of the student body, many academic libraries are beginning the project of developing a site optimized for mobile devices.

The primary considerations when designing with mobile devices in mind are in accommodating differing screen-widths, browsers, and processing speeds. An important strategy to address these issues rests in limiting clickstream. Mobile devices do not have as much processing power as personal computers and allowances must be made for this in the design process.

In order to make the most efficient use of time and effort in this project, it is best to clearly identify the purpose of the site so that it is directed by target goals. In addition, a realistic assessment of institutional competencies and support helps to inform development efforts. An appealing site will help generate use and ensure that development efforts are receptively met. Perusing the available mobile sites outside of the library community can prove an excellent development strategy.

To satisfy the peculiarities of mobile devices a number of coding strategies should be employed. Proportionally sizing text and images to accommodate screen-width variation can be accomplished through the following methods. Visual formatting for mobile devices is important and distinct from design strategies for personal computers. When undertaking the design process, important best practices to be mindful of are the use of CSS and validation services. 
A profusion of free tools and emulators exists to aid the project. 
Screen sizes present the largest variable in designing for mobile devices. They vary from approximately 120 to 480 pixels in width. Attempting to design with the limitations of each individual screen in mind is not possible. Some efforts have been made to design library sites for specific devices, such as the iPhone app available at the University of Virginia. In the process of outlining goals for a mobile project this is an issue that should be addressed. In conjunction with screen size, browser variation presents the other major variable in mobile devices.

In taking screen size variation into account, designers should make some accommodations in order to present sites that are more appealing. Images should be basic and distinct. Because of the small size of screens, it may be difficult to distinguish elements of objects or even objects themselves. Additionally, "(m)obile devices are often used outdoors. Glare can wash-out the screen, so think high-contrast for your color scheme" (Wisniewski 2010). Text should also be limited to essential information and be legible. It would not be advisable to present fonts that are not clear. In most cases users are accessing information through a mobile device for immediate use. They want hours, directions, or other information while on the go (hence the term "mobile device") so keeping that in mind designers should provide information in the most simple way possible. It is unlikely that users want several lines of text, let alone several pages, in order to get information they need. Initial interaction with mobile websites should be simple while allowing the user to access more content if desired. The effort to distill information on the site will have the benefit of adding usability while also lessening the processing burden on the device. It is important to remember that devices are not as powerful as full-sized CPU's. 
An excellent explication of browser considerations in mobile devices is available in Jeff Wisniewski's article "Mobile Websites With Minimal Effort." He outlines the present state of browser variation in mobile devices by delineating between smartphones and all other mobile devices. Smartphones are phones that have an operating system based on WebKit browsers such as Safari, those employed in Android phones that represent a Google OS, and others. Smartphones account for "more than $50 \%$ of mobile internet traffic" (Wisniewski 2010). Wisniewski outlines a development strategy which is tailored to smartphones while incorporating features that will function on other devices.

It is important to develop coding in CSS that directs mobile devices as well as smartphones to the proper site. Often, smartphones do not declare themselves to be handheld devices with the term "mobile," ignoring mobile stylesheets. In this case it is important to develop another stylesheet that directs itself to browsers of a specific screenwidth. A strategy to deal with this when designing a mobile site is to employ two style sheets, named simply mobile.css and iphone.css. Those devices that are not directed to the mobile site based on the mobile.css stylesheet will be identified and subject to the iphone.css stylesheet based upon screen-width.

Streamlining clickstream is an important factor when developing your site. Clickstream refers to the number of sites one needs to access to get the desired information. Devices are often not well-equipped to navigate through various links. This is particularly important when access keys need to be employed to use a site. This act can be frustrating and time-consuming for the user. As librarians, we want to make products that will facilitate interaction with the library and encourage future use. Additionally, cost considerations often can effect a patron's use of the site with a mobile device. If procuring 
desired information requires access to several pages this will turn the user off. Pages generally load slowly on mobile devices. Data plan subscribers often incur additional costs when using a service beyond the agreed upon amount. Limiting clickstream not only limits user frustration; it limits costs to the user, making it more likely the site will be seen as valuable. 


\section{Planning the Process}

Assess the resources available when beginning development. It is best to clearly understand the possibilities of and constraints on the project. Constraints largely dictate what is possible in the project. In certain cases, an institution will include a large computer studies program with students or faculty that can provide assistance or development support.

Identify a purpose for the project. Does the site aim to provide general information such as hours, directions, and staff directories? Does the institution place a high priority on communication between patrons and staff through mobile devices? Are the catalog or database subscription services things that are important for mobile users to have access to? The purposes of the project should be informed by patron needs or wants.

Identifying the scope and purpose of a mobile site greatly assists in the design effort. Features may be basic, such as general library information like hours and directions, or interactive, such as texting functionality and email forms. Texting is an activity the millennial generation cannot do without, as anyone who spends time in an academic library will tell you.

Texting and emailing staff are important features of a mobile site. In colleges and universities that serve many commuter and continuing education students, this presents an excellent way to enhance the learning experience. Certainly, the extension of services to communicate electronically between faculty and students represents an area of exciting possibilities and future growth. In order to generate a form for emailing a librarian, one can use Email Me Form (http://www.emailmeform.com/). This is an excellent free site which 
develops forms based on user needs. It is simple to use and presents coding which is valid. You may have to tweak the coding so that it lines up with the coding format specified on the other pages. The use of Email Me Form provides a correct form, while saving the time and frustration involved in creating forms with HTML.

It is helpful when beginning development to browse other mobile sites. A multiplicity of examples outside of the library field exists, such as the New York Times, BBC, and ESPN. Accessing sites with various devices allows you to see what works. Perhaps design or formatting styles that would work well for a library site can be discovered. It is important to remain abreast of developments outside of the academic world that appeal to users. Several fine examples of mobile sites developed for libraries exist. Impressive and informative sites have been created by the New York Public Library (http://m.nypl.org/) and Oregon State University (http://m.library.oregonstate.edu/), among others. 
Design Features

To allow text to proportionally format to varying screen-widths use percentages or ems to size text. Absolute point font sizes will not transfer well to mobile devices. A line of 20pt font text can take up an entire device screen in certain circumstances. This is unsettling. Even if a site does present all the information contained in a page, incorrectly sized text will make the scrolling necessary to access it render text useless on a mobile device. Ems and percentage are malleable values which allow browsers to scale content to fit screens. One em represents a $16 \mathrm{pt}$ font on a standard computer browser. Text can be proportionally sized by presenting different em values.

Images are an important factor in developing a visually appealing site. It is important to follow a few guidelines in employing images in a mobile site. In order to make sure images are conspicuous they should be simple and stark. Images containing gradient colors or a large color pallet may not transfer to mobile devices well. In addition, detailed images generally present a larger file size. One of the ways to minimize file size is to keep images simple. Another tool designers can employ to reduce file size is providing the images as gifs rather than jpegs. Comparable files saved as a jpeg can be several bytes larger than a gif. A consideration in minimizing load time involves incorporating them into CSS rather than HTML code. This adds consistency to a site while also simplifying the need to make changes. Rather than deal with a slew of individual HTML files to make graphic changes, they can be made by editing a few of the CSS files.

After identifying important image characteristics and file formats, designers will have to deal with the issue of image size. Unlike text, images cannot be sized in ems so an absolute size must be identified 
for images used on a site. In order to ensure consistency in appearance images should be kept to the same absolute size. Testing a beta version of a mobile site with varying devices can provide guidance regarding image sizing. An excellent source for procuring images was the Open Clipart Library (http://www.openclipart.org/). An array of images are available in an open source community.

Best practice in designing sites for mobile devices is to incorporate all stylistic elements into CSS. Incorporating all of the design elements into stylesheets has several advantages. Of particular importance for mobile devices is the benefit of reducing the size of HTML pages. This will speed up load time and, in turn, lessen costs to users. The use of stylesheets also allows the designer to make global changes to the site easily. It provides a mechanism for creating a uniform look on all pages. Another coding specification when designing for mobile devices is to avoid the use of tables. Due to the varying characteristics presented by mobile devices the use of tables presents a litany of problems.

The final step in the design process involves validation. Two tools are provided by the W3 School to undertake this, a Validator (http://validator.w3.org/) and mobileOK Checker (http://validator.w3.org/mobile/). The best point to start at is the standard HTML validator. Designers can use this to validate HTML and CSS. It is less demanding than the mobile checker so adhering to its suggestions will be less exhaustive and set you on the right path. The mobileOK Checker provides more specific evaluation for mobile devices and can take more time to satisfy. It can be intimidating to first approach validation. Initially a page may display scores of errors, yet often simple fixes remove a number of errors. Validating all code ensures that a site complies to accepted HTML standards and will appear consistently when accessed with multiple browsers. 


\section{Tools to Assist in the Development Process}

Developing a mobile site with basic HTML text editors is often most effective. Due to the limitations presented by mobile devices relating to screen width, processing speed, and other factors, mobile sites often need to be very simple in order to function properly. Editors allow the user to work with the design at the most basic level and direct designers towards simple solutions. In addition, the editors outlined in this section are cross-compatible. Documents can be saved as text and transferred between programs.

Notetab Pro (http://www.notetab.com/) is an excellent free text editor. A 30-day trial is provided for this edition. There are three editions of Notetab with the Light version available as freeware. While this program is serviceable it can become difficult to edit documents with because it does not provide text line numbers. This necessitates the purchase of the Pro version after the trial period ends.

Code Lobster (http://www.codelobster.com/) is another free editor available for download on the web. There are no distinct disadvantages when compared with Notetab Pro while presenting an obvious cost benefit. Both of these programs only work with the Windows operating system. Workarounds such as Parallels or WINE can be employed to make them function with Apple or Linux operating systems, yet the efficacy of these endeavors is questionable.

OpenOffice.org has developed an editor which is highly functional by the name of Bluefish (http://bluefish.openoffice.nl/). This program is designed to work with Linux operating systems yet it can be employed on a Mac using the WINE program if the user is savvy 
enough with applications. In many ways it is a text editor with some of the features presented by Dreamweaver. Bluefish incorporates HTML wizards, multi-language support, and other features absent from Notetab or Code Lobster while also presenting the same investment.

Dreamweaver is a powerful program yet presents many disadvantages, particularly when designing for mobile devices. An obvious drawback to working with Dreamweaver is its cost. There are more effective programs available for free. The Adobe Creative Suite does contain excellent and useful programs such as Photoshop to allow you to work with images.

Coding in documents created by Dreamweaver can be very sloppy. This is partly related to intrinsic features of the program. When handling graphics or creating a template the program inserts coding that is superfluous to HTML coding. This enables documents to access formatting or images through the use of proprietary code. While sites created by Dreamweaver can work well, this feature provides an additional level of complexity that is not desirable when designing for mobile devices. File size can become excessive. Additionally, the proprietary file formats Dreamweaver saves in are not cross compatible with other programs. While Dreamweaver does provide users the option of saving documents in formats that are universal, the code the program develops to links files and pages is not recognized by other programs and is very difficult for the user to manipulate.

Dreamweaver does provide users with a validation feature but it does not create valid code initially. Users can employ this feature throughout the process of design but even if code is validated through Dreamweaver problems may be present on mobile devices. The proprietary code referred to above can be validated but does 
present problems. When designing for mobile devices it is important to design while remaining cognizant of the fact that the processors you are designing for will not be as powerful as those of contemporary desktops.

In light of the previous discussion of browser variation on mobile devices, employing reliable device emulators in the design process is vital. A number of options will be presented that should provide an excellent starting point. Mobile devices use a variety of browsers and a coherent set of design standards has yet to be implemented for mobile browsers. Devices profiles vary widely, yet standards seem to be emerging as smartphones become more common.

The Opera browser (http://www.opera.com/), employed by many devices, is readily available for desktop use. This is an effective method for viewing how different designs would appear on devices with varying screen widths. Firefox is employed on some devices, yet the desktop version does not account for variations in screen-width. A helpful feature of Firefox is the User-Agent Switcher (https://addons.mozilla.org/en-US/firefox/addon/59/). This add-on allows the user to change the browser characteristics to those of any device. It is installed with an option to act as an iPhone. When selected, sites will appear as they do on an iPhone, even directing your browser to the mobile site in the case where that is in the code of the accessed site. A search of the internet will allow the user to find the information necessary to add different device profiles to this add-on.

Austrian web-developer Klaus Komenda has developed a site which enables users to view how a site appears on particular devices (http://www.klauskomenda.com/archives/2008/03/17/testing-onmobile-devices-using-emulators/), allowing designers to view an image of the physical device as well. This is a handy tool because it 
allows users to fully appreciate how a particular site feels with a particular device.

Dreamweaver provides a device emulation program but it is not very helpful. The program included with CS4 did not present emulators for many recently developed smartphones. Perhaps this situation has been remedied through recent updates.

Apart from employing emulators, it is helpful to test your site using Internet Explorer. It provides tangible benefits to use different incarnations, as devices vary in which version they employ. Unlike Firefox or Opera, IE is particular and dated about which code it recognizes. Certain CSS code, such as that which pertains to textshadowing or rounded button corners, is not recognized. You can chose to eliminate this code from your design or employ a different strategy such as the one Jeff Wisniewski discusses in relation to smartphones and older mobile devices. Designers can include certain code with the understanding that it will only be recognized on certain devices. If this is accounted for in the design process certain devices can present different design features on the site. 


\section{Conclusion}

The process of designing a mobile site presents many opportunities to learn and should provide a means for designers to further refine and expand upon a libraries mobile offerings. Strategies and tactics should be employed that will inform the continued development process. Contemporary academic libraries that seek to remain abreast of mobile developments counteract the tendency "(a)mong young people ... to consider the library as primarily the domain of the book" (American Library Association). The incorporation of a mobile site into a library's toolkit enables the institution to better meet the users where they are. 


\section{1}

\section{References}

American Library Association. "ACRL: Changing Roles of Academic and Research Libraries." ALA Home - American Library Association. http://www.ala.org/ala/mgrps/divs/acrl/issues/value/changingroles.cfn (accessed June 2, 2010).

Wisniewski, Jeff. "Mobile Websites With Minimum Effort." Online 34, no. 1 (January 2010): 54-57. Academic Search Complete, EBSCOhost (accessed June 2, 2010). 